\title{
Assessing the relationship between the Driver Behavior Questionnaire and the Driver Skill Inventory: Revealing sub-groups of drivers
}

\author{
Martinussen, Laila Marianne; Møller, Mette; Prato, Carlo Giacomo
}

Published in:

Transportation Research. Part F: Traffic Psychology and Behaviour

Link to article, DOI:

10.1016/j.trf.2014.06.008

Publication date:

2014

Document Version

Peer reviewed version

Link back to DTU Orbit

Citation (APA):

Martinussen, L. M., Møller, M., \& Prato, C. G. (2014). Assessing the relationship between the Driver Behavior Questionnaire and the Driver Skill Inventory: Revealing sub-groups of drivers. Transportation Research. Part F: Traffic Psychology and Behaviour, 26, 82-91. https://doi.org/10.1016/j.trf.2014.06.008

\section{General rights}

Copyright and moral rights for the publications made accessible in the public portal are retained by the authors and/or other copyright owners and it is a condition of accessing publications that users recognise and abide by the legal requirements associated with these rights.

- Users may download and print one copy of any publication from the public portal for the purpose of private study or research.

- You may not further distribute the material or use it for any profit-making activity or commercial gain

- You may freely distribute the URL identifying the publication in the public portal 
Assessing the relationship between the Driver Behavior Questionnaire and the Driver Skill Inventory: Revealing sub-groups of drivers

Laila M. Martinussen*, Mette Møller, Carlo G. Prato

DTU Transport, Bygningstorvet 116b, DK-2800 Kgs, Lyngby, Denmark

*Corresponding author. Tel. +45 452565 00; fax: +45 45936533

E-mail address: laima@transport.dtu.dk (L. M. Martinussen) 


\begin{abstract}
The Driver Behavior Questionnaire (DBQ) and the Driver Skill Inventory (DSI) are two of the most frequently used measures of self-reported driving style and driving skill. The motivation behind the present study was to test drivers' consistency or judgment of their own selfreported driving ability based on a combined use of the DBQ and the DSI. Moreover, the joint use of the two instruments was applied to identify sub-groups of drivers that differ in their potential danger in traffic (as measured by frequency of aberrant driving behaviors and level of driving skills), as well as to test whether the sub-groups of drivers differed in characteristics such as age, gender, annual mileage and accident involvement. 3908 drivers aged 18-84 participated in the survey. The results suggested that the drivers are consistent in their reporting of driving ability, as the self-reported driving skill level mirrored the self-reported frequency of aberrant driving behaviors. K-means cluster analysis revealed four distinct clusters that differed in the frequency of aberrant driving behavior and driving skills, as well as individual characteristics and driving related factors such as annual mileage, accident frequency and number of tickets and fines. These differences between the clusters suggest that two of the sub-groups are less safe than the two others, as well as heterogeneity across the population was observed. The present findings highlight the need to look into driver's attitudes towards safety, in order to improve the motivation to drive safely. Information from this study is useful for interventions to be able to target specific problematic groups of the population in the attempt to improve road safety nationwide.
\end{abstract}

Keywords: Road safety, Perceptual-motor skills, Safety skills, Driver style, DBQ, DSI, Attitudes 


\section{Introduction}

Driving style and driving skills are crucial measures when looking at a person's ability to drive in a safe and protective manner. Driving style generally refers to the way a person prefers or habitually drives the car, whereas driving skills refer to how good a person is at handling the car (Elander, West, \& French, 1993). Over the years, many measurement scales have been developed to assess both driving style and driving skills. Two instruments which have been frequently applied are the Driver Behaviour Questionnaire (DBQ, Reason, Manstead, Stradling, Baxter, \& Campbell, 1990) and the Driver Skill Inventory (DSI, Lajunen \& Summala, 1995).

The DBQ is used to measure driving style by asking how frequently drivers perform three aberrant driver behaviors, namely violations, errors and lapses. Violations are intended acts that the person is most likely aware of, for example speeding or running on red light. Errors are acts that fail to get the planned and intended outcome due to misjudgments, like breaking too abruptly. Lapses are unintentional behaviors performed because of attention or memory deficits, like missing the motorway exit (Reason et al., 1990). Violations are generally considered the most dangerous because they have shown to be the most predictive of self-reported accident involvement (de Winter \& Dodou, 2010; Glendon 2007), in both retrospect (Parker, Reason, Manstead, \& Stradling, 1995; Lawton, Parker, Manstead, \& Stradling, 1997; Rimmö \& Åberg, 1999) and prospect (Parker, West, Stradling, \& Manstead, 1995). Errors and lapses are normally not considered as dangerous as violations, however it has been shown that the two combined are as predictive of self-reported accidents as violations alone (af Wåhlberg, Dorn, \& Kline, 2009). Further, the distinction between errors and lapses on the one hand, and violations on the other, is considered crucial in traffic safety because it is analogous to the distinction between unintentional behavior and intentional behavior (Reason et al., 1990). Intentional behavior is a deliberate choice by the driver, thus the driver is by all means aware of his/her actions. Unintentional behavior stems from a different psychological 
process because it is not deliberate. Because of the different psychological processes behind the two types of behavior, it has been argued that they require different kinds of interventions or remediation (Reason et al., 1990).

Another way to assess driving behavior is through measuring self-reported driving skills. The DSI is used to measure perceptual-motor skills and safety skills. Perceptual-motor skills refer to the drivers' ability to handle the car, namely technical driving skills such as fluent and smooth car control. Safety skills, on the other hand, refer to the drivers' ability to drive in a safe manner, namely anticipatory accident avoidance skills such as driving carefully (Lajunen \& Summala, 1995). Perceptual-motor skills rely on information processing and motor skills, whereas safety skills rely on attitudes and personality factors (ibid). The distinction between safety skills and perceptual-motor skills is highlighted as the driver's internal balance between these skills-and reflects his/hers attitude to safety (ibid). This is supported by previous studies which have found drivers with high levels of perceptual-motor skills to have a more risky driving style and to be more involved in accidents than drivers with high levels of safety skills (Lajunen, Corry, Summala, \& Hartley, 1998; Sümer, Özkan, \& Lajunen, 2006). Perceptual-motor skills have also been found to positively relate to driver aggression, whereas safety skills have been found to negatively relate to driver aggression (Lajunen et al., 1998; Lajunen \& Summala, 1995, 1997). Moreover, studies have shown that especially male drivers overestimate their perceptual-motor skills (Groeger \& Brown, 1989; Lajunen et al., 1998; Lajunen \& Summala, 1995; McKenna, Stanier, \& Lewis, 1991). However, the negative effects of overconfidence resulting from exaggerated ratings of self-reported driving skills have been shown to be buffered by high levels of safety skills (Sümer et al., 2006). On the other hand, studies have also shown that drivers tend to overestimate their safety skills (Delhomme, 1991; Walton, 1999; McKenna et al., 1991). Overestimation of own driving skills have 
been found to be dangerous or unsafe, as it can lead to biased risk assessment leading to a higher risk acceptance (Deery, 1999; Groeger and Brown, 1989).

Although there are obvious differences between the instruments, there are also obvious similarities between the DBQ and the DSI. For example, perceptual-motor skills can be regarded as the ability to drive in an error-free manner and, similarly, safety skills can be regarded as the motivation and ability not to perform violations. The differences between the instruments are that the DSI measures how skilled drivers consider themselves by asking about more general traffic behaviors (i.e., “conforming to traffic rules”), while the DBQ measures how frequent drivers perform specific aberrant behaviors in traffic (i.e., “disregard traffic lights”). One could say that the DBQ and the DSI both measure driving ability, though from different perspectives. A skillful driver should ideally not perform driving aberrations too often, and therefore applying both instruments could be helpful in identifying drivers' ability to report their driving ability, in terms of overestimation and underestimation of driving skills and judgment of own self-reported driving ability.

Numerous studies have applied the DBQ and the DSI in order to look into driving style and driving skill, however, the instruments have never before been combined to test drivers' consistency when reporting driving ability or to reveal sub-groups of drivers. The combination of the DBQ and the DSI can give valuable input that neither the DBQ nor the DSI can give separately. Hypothetically, persons who are aware of their shortcomings in driving skills should also report aberrant driving behavior that reflects these limitations, and the other way around. The present study verifies whether the DBQ and the DSI are consistent, and assesses whether drivers are consistent in their reporting of their own driving abilities, by jointly analyzing the two instruments in a cluster analysis. Different from the traditional way of looking at DBQ and DSI data (where principal component analysis or exploratory factor analysis are performed in order to look into the 
factor structure within a population), the current study wants to explore the data based on similar and dissimilar drivers. Cluster analysis is used to explore the data based on objects, giving information about similar groups of answers in the population (Kaufman \& Rousseeuw, 1990). Moreover, the literature generally reports that drivers vary in driving style and driving skills between genders, age-groups and experience levels (Lajunen et al., 1998; Lajunen \& Summala, 1995; Lawton et al., 1997; Özkan \& Lajunen, 2006; Reason et al., 1990; Rimmö 2002; Rimmö \& Hakamies-Blomqvist, 2002; Åberg \& Rimmö, 1998). Thus, the present study intends to exploit the opportunity to see whether the DBQ and the DSI can jointly uncover heterogeneity across the population by identifying sub-groups of drivers that potentially present different problems in traffic safety. As both the DBQ and the DSI have been shown to be correlated with self-reported accident involvement (af Wåhlberg et al., 2009; de Winter \& Dodou, 2010; Glendon 2007; Lajunen et al., 1998; Lawton et al., 1997; Parker et al., 1995a, b; Rimmö \& Åberg, 1999), this is useful for interventions to be able to target specific problematic sub-groups of the population in the attempt to improve road safety.

On the basis of the above, the present study aims were: (1) to see whether the DBQ results reflect the answers in the DSI and vice versa, thus indicating to which extent drivers show consistency in their judgment of their driving ability; (2) to test whether sub-groups differing in their potential danger in traffic could be identified on the basis of the DBQ and the DSI, as well as background characteristics such as age, gender and driving frequency.

\section{Method}

\subsection{Participants and procedure}

A sample of 11,004 drivers between 18-84 years old with minimum type B driver license (license for private car in Denmark) was randomly selected from the Danish Driving License Register. The sample included 1,572 drivers in each of the following seven age groups; 18-24 years, 25-34 years, 
35-44 years, 45-54 years, 55-64 years, 65-74 years, 75-84 years (786 men and women in each age group). A questionnaire containing background variables, the DBQ and the DSI, a cover letter and a freepost return envelope, were sent by post to all selected participants. The DBQ and the DSI were translated into Danish using back-translation, namely they were first translated into Danish, and then back to English again to assure similar meaning. The questionnaire also included a web address that the respondents could use to reply. Participants responded to the questionnaire anonymously. Two reminders were sent out and 4,849 persons responded to the survey. Of the 4,849 answers, 3,908 persons had completed all of the DBQ and the DSI questions leading to the final response rate of $35.51 \%$. The Danish Data Protection Agency had approved the survey. Sample characteristics can be found in Table 1.

Table 1 about here

\subsection{Instruments}

Firstly, participants were asked to indicate their age, gender and area code, annual mileage, accidents and fines during the last three years, as well as normal and preferred speed on various road types. Secondly, the participants answered the DBQ. The DBQ is used to assess aberrant driver behavior by asking how often drivers perform violations, errors and lapses on a six-point Likert scale ( $0=$ never, $5=$ nearly all the time) across 50 different driver behaviors (for a detailed description see Reason et al., 1990). Since the original DBQ study by Reason et al. (1990) only reported factor loadings above 0.50 , 27 of the original 50 items were used in the current study as “the original DBQ” (see Table 2). Lastly, the participants answered the DSI. The DSI measures perceptual-motor skills and safety skills by asking drivers how skillful they consider themselves to be on a five-point scale ( 0 = well below average, $4=$ well above average) across 25 different driving situations (see Table 2). 


\subsection{Statistical analysis}

Firstly, Reason et al. (1990) and Lajunen and Summala (1995) factor structures were applied in the present study, as they are the original structures of the two scales. Furthermore, Reason et al.'s (1990) DBQ structure has previously been tested with a confirmatory factor analysis in the same sample as the current, and shown good fit, even across sub-groups of drivers (Martinussen, Hakamies-Blomqvist, Møller, Lajunen \& Özkan, in press). The cut-off point used in Reason et al.’s (1990) principal component analysis was 0.50 . For the DSI, items that loaded above 0.40 in the original study were included in the current analysis (except item 6 from the original scale, as it seems to be covered by item 8 which loaded higher in the original study, see Lajunen \& Summala, 1995). Secondly, Cronbach's alpha values of the DBQ and the DSI factors were calculated in order to check if the internal consistency of each item was sufficiently high. Thirdly, sum scores of items loading on violations, errors and lapses and on perceptual-motor skills and safety skills were calculated. When applying two different measurement scales (DBQ, DSI), it is necessary to make the scales comparable in order to avoid the problem of comparing squared Euclidean distances and thereby having different scales. This was done by using standardized scores of the five factors sum scores (two DSI, three DBQ). Fourthly, sub-groups of drivers were identified by applying the standardized scores of the factors as input variables in a cluster analysis with k-means algorithm (Kaufman \& Rousseeuw, 1990). In a k-means clustering each data point is assigned to the closest cluster as the K-means cluster algorithm minimizes the sum of the squared distances from the cluster means and groups individuals on the basis of patterns that are similar in their answers or scores (Kanungo, Netanyahu, \& Wu, 2002). The optimal cluster solution is reached with the minimum squared error that indicates the clusters being better representative of the data (Tan, 
Steinbach, \& Kumar, 2005). Three to eight cluster solutions were tested. Choosing the optimal number of clusters can be a problem because of local minima (Tan et al., 2005). The various cluster solutions were compared according to the interpretability and predictive power. Analysis of variance (ANOVA) can be applied to assess the predictive power, thus F-values and $\eta^{2}$-values were used to determine the number of clusters best fitting the data. Finally, ANOVA post hoc test (Gabriel and Hochberg) was performed to see whether the clusters differed from each other on the basis of age, gender and area code, annual mileage, number of accidents and fines, as well as normal and preferred speed on various road types.

\section{Results}

\subsection{The cluster solution}

The items included in the three DBQ factors and the two DSI factors which were used as input variables in the cluster analysis can be seen in Table 2. All five factors had acceptable high Cronbach’s alpha values indicating good internal consistency (see Table 2). Acceptable high Cronbach's alpha is 0.70 and above (Cortina, 1993), which is also in line with the original DBQ study and other previous DBQ studies (see Lajunen, Parker, \& Summala, 2004; Özkan, Lajunen, Chliaoutakis, Parker, \& Summala, 2006a; Reason et al., 1990). Mean standardized scores for the variables used in the k-means cluster analysis can be seen in Table 3. A four cluster solution was decided upon because F-values and $\eta^{2}$-values were slightly better than the other five solutions (see

Table 4). This four cluster solution is highly interpretable and clearly illustrates four distinct driver sub-groups which differ in their driving style and driving skills. The profile plot of the four cluster solution can be seen in Figure 1. 
Table 3 about here

Table 4 about here

\subsection{The four cluster profiles}

The characteristics of the drivers in all four clusters are shown in Table 5. The normal and preferred speeds of the drivers in the different clusters are shown in Table 6. Based on variations in perceptual-motor skills, safety skills, violations, errors and lapses, cluster one to four can respectively be labeled: “skilled safe drivers”, “violating unsafe drivers”, “unskilled unsafe drivers”, and "unskilled safe drivers".

In the first cluster, the "skilled safe drivers", $58 \%$ are men and $46 \%$ of the drivers are below the age of 55 years old. This cluster is characterized by high perceptual-motor and safety skills, and low frequency of violations, errors and lapses. This indicates that the drivers belonging to this cluster drive more safely, as they seem to be both safety oriented and perceptual-motor skilled. This is also reflected in their low frequency of aberrant behaviors. This cluster also has the lowest percentage of drivers who have had one or more accidents, and the second highest $\mathrm{km} / \mathrm{year}$ of the four clusters.

Cluster two, the "violating unsafe drivers", consists of the highest percentage of men (74\%) and has the highest $\mathrm{km} /$ year out of the four clusters. $85 \%$ of the drivers in this cluster are below the age of 55 years old, making this the cluster the youngest sub-group. They report the lowest levels in safety skills, but the second highest levels of perceptual-motor skills. With the highest frequency of violations and the second highest frequency of errors and lapses, these drivers seem to be driving in the most risky way. They also have the highest percentage of accidents and fines, highest normal and preferred speed, in addition to the highest frequency of violations and lowest safety skill level. 
Drivers in cluster three, the “unskilled unsafe drivers”, report low levels of perceptualmotor skills, safety skills and number of violations, but the highest number of both errors and lapses. This cluster consists of 59\% women, and 56\% of the drivers in this cluster are below the age of 55 years old. Similar to cluster two, this cluster also seems to be composed of drivers who are taking risks, as they report the second highest number of accidents and fines. These drivers report to drive the second least $\mathrm{km} /$ year.

Drivers in the fourth cluster, the "unskilled safe drivers” drive the least km/year. The cluster consists of $60 \%$ women, and $46 \%$ of the drivers are below the age of 55 years old. They report the second lowest number of violations, errors and lapses, as well as very low levels in both safety skills and perceptual-motor skills. The significant differences between the four clusters can be seen in superscript in Table 5 and Table 6.

\section{Table 5 about here}

\section{Table 6 about here}

\section{Discussion}

The aim of the current study was twofold. Firstly, we wanted to combine answers from the DBQ and the DSI to verify the consistency of the two instruments, thus testing if the drivers have a consistent judgment of their own driving ability. Secondly, we wanted to test whether sub-groups of drivers differing in their potential danger in traffic could be separated on the basis of the DBQ and the DSI answers, as well as showing heterogeneity in characteristics such as age, gender and driving frequency. The cluster analysis revealed four distinct clusters differing in their DBQ and DSI profiles. The DBQ and the DSI responses reflected each other in a sensible way, which shows consistency between the instruments. Low levels of self-reported skills were mirrored by a high frequency of self-reported aberrant behavior, and vice versa, in three of the four sub-groups of 
drivers, indicating consistency in the drivers self-reported driving ability. Further, differences regarding age, gender, annual mileage, accidents and fines, and normal and preferred speed were found, thus showing heterogeneity among the clusters. The results supports previous results indicating a need for a differentiated preventive strategy taking age, gender, exposure and risk profile into account.

\subsection{Drivers self-reported driving ability}

Separately, the DBQ and the DSI have previously shown to be predictive of selfreported accident involvement which indicates that they are good instruments for measuring how safe or unsafe drivers are in traffic. Another way to assess drivers potential unsafe driving is through assessing drivers' judgment of own driving ability. As the DBQ and the DSI measure two different aspects of driving ability, the current hypothesis was that it is possible to see whether drivers have a consistent view of their self-reported driving ability by examining the consistency between the two instruments. Unlike previous findings (e.g. Delhomme, 1991; McKenna, 1993; Walton, 1999), the present results suggest that overconfidence in self-reported driving skills might not be a significant problem within the current population. Drivers in clusters one, two and three seem to have a consistent view of their driving ability indicated by a reported driving skill level that mirrors the frequency of reported aberrant behaviors. If these drivers were overconfident in their driving skills, then the relation between the DBQ and the DSI answers should not be as consistent as the present findings suggest. Previous studies have highlighted that drivers should undergo training that improves self-awareness about their real driving skills in order to prevent a false sense of safety and overconfidence (Özkan, Lajunen, Chliaoutakis, Parker, \& Summala, 2006b). However, the current study results suggest that lack of self-awareness in own driving skills is not a major problem, at least not when the skills are self-reported. The drivers seem to be aware of both 
their high and low driving skill levels, as well as their frequencies of aberrant behaviors, which fit their reported driving skill level. However, the results show one exception to this as the drivers in cluster four report both low safety and perceptual-motor skills, and low frequency of violations, errors and lapses. A possible explanation could be that this cluster consists of the second oldest drivers where more than half are women. Previous findings suggest that older women rate their driving skills less positive than men (Ruechel \& Mann, 2005) and also have lower confidence in their driving (D’Ambrosi, Donofio, Coughlin, Mohyde, \& Meyer, 2008). Considering this, the lack of consistency between the DBQ and the DSI found in relation to cluster four is not surprising. These drivers seem to be under-confident, rather than overconfident or to lack insight into their driving ability, as their reported low frequency of aberrant driving behavior is not reflected in their reported driving skill level. This indicates that drivers in cluster four, contrarily to the drivers in the other three clusters, might benefit from a driving skill confidence course, or a driving skill awareness course.

\subsection{Sub-groups of drivers}

The present findings suggest that the DBQ and the DSI are suitable instruments for identifying sub-groups of drivers that differ in how potentially dangerous or unsafe drivers they are. Being aware of the recent discussion in the literature of the DBQs predictive validity of accidents (af Wåhlberg \& de Winter, 2012), the current study supports the notion that self-report measures such as the DBQ and the DSI have an important value in the traffic safety work. The present findings show that the four clusters clearly differ in number of accidents and fines, annual mileage and speed preferences as well as driving style and driving skills, indicating that two sub-groups could be considered more unsafe and two could be considered safer. "Unsafe" is here justified by the fact that cluster two and three report low levels of driving skills in at least one of the two driving 
skill categories, high frequency in one or more of the three aberrant behaviors, and the highest number of accidents and fines, and highest normal and preferred speed. Previous studies have shown that self-reported violations, errors and lapses are correlated with self-reported accident involvement (af Wåhlberg et al., 2009; de Winter \& Dodou, 2010; Lawton et al., 1997; Rimmö \& Åberg, 1999; Parker et al., 1995a, b). Moreover, persons who report high levels of perceptual-motor skills have also reported a more risky driving style which has been reflected through number of selfreported accidents and penalties, and level of speed, while high levels of safety skills have been negatively related to these variables (Hatakka, Keskinen, Gregersen, Glad, \& Hernetkoski, 2002; Lajunen, Corry, Summala, \& Hartley, 1998; Özkan et al., 2006b; Sümer et al., 2006). The present findings suggest a similar pattern, as drivers in cluster two report high levels of perceptual-motor skills, low levels of safety skills and the highest frequency of violations, number of tickets and fines. Because violations and safety skills are attitude based, one might argue that the number of tickets and fines a driver has received could reflect the drivers' attitudes towards safety. Thus, a high frequency of violations and a large number of tickets and fines could indicate a higher tolerance for law and rule breaking. Additionally, cluster two reports the highest normal and preferred speed. As accidents are rare events, speed has previously been used as an indicator for riskiness (Lajunen et al., 1998) which the current results also could indicate.

The other group which could be considered unsafe is cluster three. The drivers in this cluster report low levels in both types of driving skills, which could be argued to be even more hazardous than low levels in one of the two driving skill categories. Low levels on both perceptualmotor skills and safety skills have been found to correlate positively with self-reported hostile aggression and revenge feelings while driving (Sümer et al., 2006). Similarly, it has been suggested that shortcomings in driving skills make the drivers become frustrated and disappointed, leading to aggressive behavior in traffic (ibid.). The drivers in cluster three also report the highest frequency of 
errors and lapses, which previously have been found to be nearly as predictive or as predictive of self-reported accident involvement as violations alone (af Wåhlberg et al., 2009; de Winter \& Dodou, 2010). Therefore, cluster three could also be considered to be a dangerous or unsafe driver sub-group, despite being quite different from cluster two.

The drivers in cluster one and four seem to be safer than the two other clusters because they report the lowest frequency of aberrant driving behaviors. The drivers in cluster one also have the highest reported level in both safety and perceptual-motor skills. However, drivers in cluster four report the lowest level of perceptual-motor skills and the second lowest level of safety skills. Even though these drivers do not consider themselves very skilled drivers, this is not supported by their reported frequency of aberrant driving behavior, or accidents and fines. Therefore, and as mentioned above, is seems likely that they are under-confident, rather than unskilled.

\section{3 Implications of the present results}

For interventional purposes, the results indicate the relevance of splitting possible problem areas in driving into three categories: actual driving skills, attitude towards safety and selfassessment. Firstly, we have the actual driving skills which here refer to the perceptual-motor skills and the frequency of errors and lapses. Practice and training is needed to improve these skills. Secondly, we have the attitude towards safety which refers to safety skills and frequency of violations. An attitude change is needed to improve these skills. Thirdly, we have self-assessment. In order to be able to change the other two aforementioned, it is crucial to be aware of own shortcomings in both driving skills and style. In addition, it is important to know why and how to adjust for own shortcomings in order to get the motivation to change. 
The results indicate that awareness of shortcomings in driving skills and style seems to be present in all clusters with the exception of cluster four. Drivers in cluster three need help with their actual driving skills as well as their attitude towards safety, whereas drivers in cluster two only needs help with their attitude towards safety. Drivers in cluster two and three seem to be aware of their aberrant driving and low driving skills, which raises the question of why they do not do something about it. Previous studies have highlighted that violators have a false perception of their driving skills due to overconfidence (Özkan \& Lajunen, 2006). Consequently, it could be that committing violations is not considered a safety problem, as high levels of perceptual-motor skills may be expected to compensate for the extra workload that engaging in driving violations possesses. However, this explanation does not seem to apply to the drivers from cluster two, as they also report low levels of safety skills, thereby admitting to be less skilled. A more plausible explanation stems from observational learning (Bandura, 1977). Drivers learn from the effect and expected mastery of own behavior, and because drivers receive differential feedback from driving and the majority of drivers never experience an accident, this might result in an attitude that they do not 'need' to take safety precautions into account. Thus, a high level of exposure without accidents could lead to a decrease in the perception of subjective risk and lower safety concern (Lajunen \& Summala, 1995; Näätänen \& Summala, 1976). Combined with a high level of perceptual-motor skills, this could make drivers believe that they can handle driving in an unsafe or risky manner without posing a threat to themselves or others, thus leading drivers to consider safety skills to be less important. This might also explain why drivers in cluster three do not remedy their low levels of perceptual-motor skills and safety skills, as the majority has never received any negative feedback indicating the potential danger of a low level of driving related skills. On the other hand, the fact that driver training, information campaigns and media highlight the danger of risky driving, as for example speeding (Delhomme, Grenier, \& Kreel, 2008), drivers should, in theory, be aware 
of the danger posed by such acts. If the driver is aware, but do not make changes in their behavior, then that could also indicate a negative attitude towards traffic safety or a result of optimism bias (DeJoy, 1989). Even though the highest amount of accidents and fines are found in cluster two and three, these events are still rare and might therefore not have an impact strong enough for a behavioral change.

Results indicate that the drivers in both cluster two and three do need attitudinal changes based on the lowest level of reported safety skills, as well as the highest reported frequency of violations (only cluster two). Campaigns are widely used in order to change attitudes towards road safety. However, there are currently no clear cut methods available for effectively changing attitudes (Hoekstra \& Wegman, 2011). Nevertheless, this study underlines that the area of attitude change and evaluation of methods for attitude change, is crucial and should be explored further. Finally, in line with previous results, the results of this study indicate the relevance of using a differentiated approach including a combination of several intervention strategies (Delhomme, De Dobbeleer, Forward, \& Simoes, 2009) in order to account for the differences in driver behavior and differences in the psychological processes behind accident involvement.

In the future, additional exploration of the differences between the clusters should be performed including more information about the drivers such as socio-demographic factors. This would give a better understanding of the sub-groups and also help to further understand what could motivate a behavioral and attitudinal change.

A limitation of the current study is that we rely on self-reported data only. Recent literature discusses the predictability of self-report measures, without however reaching an agreement (af Wåhlberg \& de Winter, 2012). In line with this discussion, future studies should look into the link between actual driving style and skill, versus self-reported driving style and skill. The link between self-reported behavior and actual behavior has been explored in a recent study, where 
however the sample size was spare and thus the results should be interpreted with caution (Underwood, 2012). Other previous studies on this relationship do not indicate clear coherence between the two (for more information see af Wåhlberg \& de Winter, 2012; Sundström, 2008), indicating the need for further exploration of this field.

\section{Acknowledgment}

We are grateful to the Danish Council for Strategic Research (Det Strategiske Forskningsråd) for financial support, to Sonja Haustein for methodological input, and finally for insightful remarks provided during the review process.

\section{References}

Af Wåhlberg, A., \& de Winter, J.C.F. (2012). Commentaries and responses to "The Driver Behavior Questionnaire as a predictor of accidents: A meta-analysis”. Journal of Safety Research, 43, 83-99.

Af Wåhlberg, A., Dorn, L., \& Kline, T. (2009) The Manchester driver behavior questionnaire as a predictor of road traffic accidents. Theoretical Issues in Ergonomics Science, 12 (1), 66-86.

Bandura, A. (1977). Self-efficacy: Toward a unifying theory of behavioral change. Psychological Review, 84 (2), 191-215.

D’Ambrosi, L.A., Donofio, L.K.M., Coughlin, J.F., Mohyde, M., \& Meyer, J. (2008). Gender differences in self-regulation patterns and attitudes toward driving among older adults. Journal of Women \& Aging, 20 (3/4), 265-282.

De Winter, J.C.F., \& Dodou, D. (2010). The driver behavior questionnaire as a predictor of accidents: a meta-analysis. Journal of Safety Research, 41, 463-470. 
Deery, H. A. (1999). Hazard and risk perception among young novice drivers. Journal of Safety Research, 30, 225-236.

DeJoy, D.M. (1989). The optimism bias and traffic accident risk perception. Accident Analysis and Prevention, 21 (4), 333-340.

Delhomme, P. (1991). Comparing one’s driving ability with others: assessment of abilities and frequency of offences. Evidence for a superior conformity of self-bias. Accident Analysis and Prevention, 23 (6), 493-508.

Delhomme, P., De Dobbeleer, W., Forward, S., \& Simoes, A. (Eds.). (2009). Manual for designing, implementing and evaluating road safety communication campaigns. Brussels: Belgian Road Safety Institute.

Delhomme, P., Grenier, K., \& Kreel, V. (2008). Replication and extension: The effect of the commitment to comply with speed limits in rehabilitation training courses for traffic regulation offenders in France. Transportation Research Part F, 11, 192-206.

Elander, J., West, R., \& French, D. (1993). Behavioral correlates of individual differences in road traffic crash risk: an examination of methods and findings. Psychological Bulletin, 113, 279_ 294.

Glendon, A.I. (2007). Driving violations observed: An Australian study. Ergonomics, 50 (8), 11591182.

Groeger, J.A., \& Brown, I.D. (1989). Assessing one’s own and others’ driving ability: influences of sex, age, and experience. Accident Analysis and Prevention, 21, 155-168.

Hatakka, M., Keskinen, E., Gregersen, N. P., Glad, A. \& Hernetkoski, K. (2002). From control of the vehicle to personal self-control; broadening the perspective to driver education. Transportation Research F, 5, 201-215. 
Hoekstra, T., \& Wegman, F. (2011). Improving the effectiveness of road safety campaigns: current and new practices. IATSS Research, 34, 80-86.

Kanungo, T., Netanyahu, N.S., \& Wu. A.Y. (2002). An efficient k-means clustering algorithm: Analysis and implementation. IEEE Transactions on Pattern Analysis and Machine Intelligence, 24 (7), 881-892.

Kaufman, L., \& Rousseeuw, P.J. (1990). Finding groups in data: An introduction to cluster analysis. New York: Wiley.

Lajunen, T., Corry, A., Summala, H., \& Hartley, L. (1998). Cross-cultural differences in drivers self assessment of their perceptual-motor and safety skills: Australian and Finns. Personal Individual Differences, 24 (4), 539-550.

Lajunen, T., Parker, D., \& Summala, H. (2004). The Manchester driver behaviour questionnaire: a cross-cultural study. Accident Analysis and Prevention, 36 (2), 231-238.

Lajunen, T., \& Summala, H. (1995). Driving experience, personality, and skill and safety-motive dimensions in drivers’ self-assessments. Personality and Individual Differences, 19 (3), 307 318.

Lajunen, T., \& Summala, H. (1997). Effects of driving experience, personality, and driver's skill and safety orientation on speed regulation and accidents. In T. Rothengatter \& E. Carbonell Vaya (eds.), Traffic and transport psychology: Theory and application (pp.283-294). Amsterdam: Pergamon.

Lawton, R., Parker, D., Manstead, A., \& Stradling, S.G. (1997). The role of affect in predicting social behaviours: the case of road traffic violations. Journal of Applied Social Psychology, 27, 1258-1276. 
Martinussen, L. M., Hakamies-Blomqvist, L., Møller, M., Lajunen, T., \& Özkan, T. Age, gender, mileage and the DBQ: the validity of the Driver Behaviour Questionnaire in different driver groups. Accident Analysis and Prevention, DOI: 10.1016/j.aap.2012.12.036.

McKenna, F.P. (1993). It won’t happen to me: unrealistic optimism or illusion of control? British Journal of Psychology, 84, 39-50.

McKenna, F.P., Stanier, R.A., \& Lewis, C. (1991). Factors underlying illusory self-assessment of driving skills in males and females. Accident Analysis and Prevention, 23 (1), 45-52.

Näätänen, R., \& Summala, H. (1976). Road-user behavior and traffic accidents. Amsterdam and New York: North/Holland/American Elsevier.

Özkan, T., \& Lajunen, T. (2006). What causes the difference in driving between young men and women? The effects of gender roles and sex on young drivers' behavior and self-assessment of skills. Transportation Research Part F, 9, 269-277.

Özkan, T., Lajunen, T., Chliaoutakis, J., Parker, D., \& Summala, H. (2006)a. Cross-cultural differences in driving behaviours: a comparison of six countries. Transportation Research Part F, 9 (3), 227-242.

Özkan, T., Lajunen, T., Chliaoutakis, J., Parker, D., \& Summala, H. (2006)b. Cross-cultural differences in driving skills: A comparison of six countries. Accident Analysis and Prevention, 38, 1011-1018.

Parker, D., Reason, J., Manstead, A., \& Stradling, S.G. (1995)a. Driving errors, driving violations and accident involvement. Ergonomics, 38 (5), 1036-1048.

Parker, D., West, R., Stradling, S.G., \& Manstead, A. (1995)b. Behavioral characteristics and involvement in different types of traffic accidents. Accident Analysis and Prevention, 27, 571581. 
Reason, J. T., Manstead, A., Stradling, S.G., Baxter, J., \& Campbell, K. (1990). Errors and violations on the road - a real distinction. Ergonomics. 33 (10/11). 1315-1332.

Rimmö, P-A. (2002). Aberrant driver behavior: homogeneity of a four-factor structure in samples differing in age and gender. Ergonomics, 45 (8), 569-582.

Rimmö, P.-A., \& Hakamies-Blomqvist, L. (2002). Older drivers’ aberrant driving behaviour

Formatted: Danish impaired activity, and health as reasons for self-imposed driving limitations. Transportation Research Part F, 5 (1), 47-62.

Rimmö, P-A., \& Åberg, L. (1999). On the distinction between violations and errors: sensation seeking associations. Transportation Research Part F, 2, 151-166.

Ruechel, S. \& Mann, W.C. (2005). Self-regulation of Driving by Older Persons. Physical and Formatted: English (U.S.) Occupational Therapy in Geriatrics, 23, 91 - 102.

Sümer, N., Özkan, T., \& Lajunen, T. (2006). Asymmetric relationship between driving and safety skills. Accident Analysis and Prevention, 38, 703-711.

Sundstöm, A. (2008). Self-assessment of driving skill - A review from a measurement perspective. Transportation Research Part F, 11, 1-9.

Underwood, G. (2012). On-road behavior of younger and older novices drivers during the first six months of driving. Accident Analysis and Prevention, doi: 10.1016/j.aap.2012.03.019.

Tan, P-N., Steinbach, M., \& Kumar, V. (2005). Introduction to data mining. Pearson Addison Wesley.

Walton, D. (1999). Examining the self-enhancement bias: professional truck drivers perception of speed, safety, skill and consideration. Transport Research Part F, 4, 279-297.

Åberg, L., \& Rimmö, P.-A. (1998). Dimensions of aberrant driver behaviour. Ergonomics, 41 (1), 39-56. 
Table 1

Sample characteristics

\begin{tabular}{llll}
\hline & Total & Males & Females \\
\hline$N$ & 3893 & 2038 & 1855 \\
Age & & & \\
Mean & 51.21 & 53.14 & 49.01 \\
St. D & 18.11 & 18.53 & 17.38 \\
Annual mileage $(\mathrm{km})$ & & & \\
Mean & 14517.67 & 17464.05 & 11237.82 \\
St. D & 12487.60 & 13027.74 & 10972.96 \\
\hline
\end{tabular}

\begin{tabular}{|c|c|c|c|c|}
\hline \multicolumn{5}{|c|}{$\begin{array}{l}\text { Table } 2 \\
\text { The constitute variables with their individual items and Cronbach's alpha values }\end{array}$} \\
\hline $\begin{array}{l}\text { P-Motor skills } \\
\alpha=0.935\end{array}$ & $\begin{array}{l}\text { Safety skills } \\
\alpha=0.889\end{array}$ & $\begin{array}{l}\text { Violations } \\
\alpha=0.728\end{array}$ & $\begin{array}{l}\text { Errors } \\
\alpha=0.767\end{array}$ & $\begin{array}{l}\text { Lapses } \\
\alpha=0.683\end{array}$ \\
\hline $\begin{array}{l}\text { 1) Fluent driving } \\
\text { (management of your car } \\
\text { in heavy traffic) }\end{array}$ & $\begin{array}{l}\text { 7) Conforming to the } \\
\text { traffic rules }\end{array}$ & $\begin{array}{l}\text { 2) Unknowingly } \\
\text { speeding }\end{array}$ & $\begin{array}{l}\text { 11) Turn right on } \\
\text { to vehicle's path }\end{array}$ & $\begin{array}{l}\text { 8) Forget where } \\
\text { car is }\end{array}$ \\
\hline $\begin{array}{l}\text { 2) Performance in a } \\
\text { critical situation }\end{array}$ & 10) Driving carefully & $\begin{array}{l}\text { 4) Overtake on the } \\
\text { inside }\end{array}$ & $\begin{array}{l}\text { 20) Try to pass } \\
\text { without using } \\
\text { mirror }\end{array}$ & $\begin{array}{l}\text { 10) Intend lights } \\
\text { but switch on } \\
\text { wipers }\end{array}$ \\
\hline $\begin{array}{l}\text { 3) Perceiving hazards in } \\
\text { traffic }\end{array}$ & $\begin{array}{l}\text { 15) Paying attention to } \\
\text { other road users }\end{array}$ & $\begin{array}{l}\text { 5) Drive as fast on } \\
\text { dipped lights }\end{array}$ & $\begin{array}{l}\text { 28) Fail to see } \\
\text { pedestrian waiting }\end{array}$ & $\begin{array}{l}\text { 14) Miss motorway } \\
\text { exit }\end{array}$ \\
\hline $\begin{array}{l}\text { 4) Driving in a strange } \\
\text { city }\end{array}$ & $\begin{array}{l}\text { 19) Avoiding } \\
\text { competition in traffic }\end{array}$ & 7 ) Close follow & $\begin{array}{l}\text { 30) Misjudge } \\
\text { speed of ongoing } \\
\text { vehicle }\end{array}$ & $\begin{array}{l}\text { 15) Forget which } \\
\text { gear }\end{array}$ \\
\hline $\begin{array}{l}\text { 8) Managing the car } \\
\text { through a skid }\end{array}$ & $\begin{array}{l}\text { 20) Keeping sufficient } \\
\text { following distance }\end{array}$ & $\begin{array}{l}16 \text { ) Risky } \\
\text { overtaking }\end{array}$ & $\begin{array}{l}\text { 32) Fail to see } \\
\text { pedestrian } \\
\text { stepping out }\end{array}$ & $\begin{array}{l}\text { 17) On usual route } \\
\text { by mistake }\end{array}$ \\
\hline $\begin{array}{l}\text { 9) Prediction of traffic } \\
\text { situations ahead }\end{array}$ & $\begin{array}{l}\text { 21) Adjusting your speed } \\
\text { to the conditions }\end{array}$ & 18) Shoot lights & $\begin{array}{l}\text { 41) Manoeuvre } \\
\text { without checking } \\
\text { mirror }\end{array}$ & $\begin{array}{l}\text { 37) Get into the } \\
\text { wrong lane at } \\
\text { roundabout }\end{array}$ \\
\hline $\begin{array}{l}\text { 11) Knowing how to act } \\
\text { in particular traffic } \\
\text { situations }\end{array}$ & $\begin{array}{l}\text { 24) ‘Relinquishing’ } \\
\text { legitimate rights when } \\
\text { necessary }\end{array}$ & $\begin{array}{l}\text { 19) Angry, give } \\
\text { chase }\end{array}$ & $\begin{array}{l}\text { 42) Try to pass } \\
\text { vehicle turning } \\
\text { right }\end{array}$ & $\begin{array}{l}\text { 38) Wrong exit } \\
\text { from roundabout }\end{array}$ \\
\hline $\begin{array}{l}\text { 12) Fluent lane-changing } \\
\text { in heavy traffic }\end{array}$ & $\begin{array}{l}\text { 25) Conforming to the } \\
\text { speed limits }\end{array}$ & $\begin{array}{l}\text { 21) Disregard the } \\
\text { speed at night }\end{array}$ & $\begin{array}{l}\text { 46) Fail to see } \\
\text { pedestrians } \\
\text { crossing }\end{array}$ & \\
\hline 13) Fast reactions & $\begin{array}{l}\text { 26) Avoiding } \\
\text { unnecessary risks }\end{array}$ & $\begin{array}{l}\text { 44) Disregard } \\
\text { traffic lights late } \\
\text { on }\end{array}$ & & \\
\hline $\begin{array}{l}\text { 14) Making firm } \\
\text { decisions }\end{array}$ & $\begin{array}{l}\text { 27) Tolerating other } \\
\text { drivers' blunders calmly }\end{array}$ & $\begin{array}{l}\text { 45) Only half-an- } \\
\text { eye on the road }\end{array}$ & & \\
\hline $\begin{array}{l}\text { 16) Driving fast if } \\
\text { necessary }\end{array}$ & $\begin{array}{l}\text { 28) Obeying the traffic } \\
\text { lights carefully }\end{array}$ & 47) Have races & & \\
\hline 17) Driving in the dark & & 48) Race for a gap & & \\
\hline
\end{tabular}




\begin{tabular}{|l|l|l|l|l|}
\hline $\begin{array}{l}\text { 18) Controlling the } \\
\text { vehicle }\end{array}$ & & & \\
\hline 22) Overtaking & & & \\
\hline Note. Numbers in front of items are item-numbers in the original scales. & & \\
\hline
\end{tabular}

Table 3

Mean standardized scores on the measures defining the four sub-groups of drivers

\begin{tabular}{lllll}
\hline Clusters & 1 & 2 & 3 & 4 \\
\hline Violations & -0.47 & 1.44 & -0.22 & -0.48 \\
Errors & -0.56 & 0.25 & 1.28 & -0.40 \\
Lapses & -0.57 & -0.04 & 1.28 & -0.22 \\
P-Motor skills & 0.83 & 0.53 & -0.53 & -0.68 \\
Safety skills & 0.92 & -0.69 & -0.25 & -0.43 \\
\hline
\end{tabular}

Table 4

ANOVA results for the different number of clusters

\begin{tabular}{|c|c|c|c|c|c|c|}
\hline \multirow[t]{2}{*}{$\begin{array}{l}\text { Number of } \\
\text { clusters }\end{array}$} & \multicolumn{2}{|c|}{ Annual mileage } & \multicolumn{2}{|l|}{ Age } & \multicolumn{2}{|l|}{ Gender } \\
\hline & $\eta^{2}$ & $\mathrm{~F}$ & $\eta^{2}$ & $\mathrm{~F}$ & $\eta^{2}$ & $\mathrm{~F}$ \\
\hline 3 & .018 & $34.821^{* *}$ & .048 & $98.057 * *$ & .026 & $52.808 * *$ \\
\hline 4 & .060 & $83.514^{* *}$ & .102 & $147.235 * *$ & .065 & $89.940 * *$ \\
\hline 5 & .056 & $58.101 * *$ & .097 & $105.085^{* *}$ & .070 & $72.973 * *$ \\
\hline 6 & .065 & $54.493 * *$ & .115 & $101.754 * *$ & .070 & $58.741 * *$ \\
\hline 7 & .066 & $46.037 * *$ & .112 & $81.995 * *$ & .071 & $49.920 * *$ \\
\hline 8 & .070 & $42.228 * *$ & .109 & $67.905 * *$ & .082 & $49.888 * *$ \\
\hline
\end{tabular}

Note. ${ }^{* *} p<.001$.

Table 5

Characteristics of the four clusters

\begin{tabular}{lllll}
\hline & $\begin{array}{l}\text { Skilled } \\
\text { safe } \\
\text { drivers }\end{array}$ & $\begin{array}{l}\text { Violating } \\
\text { unsafe } \\
\text { drivers }\end{array}$ & $\begin{array}{l}\text { Unskilled } \\
\text { unsafe } \\
\text { drivers }\end{array}$ & $\begin{array}{l}\text { Unskilled } \\
\text { safe } \\
\text { drivers }\end{array}$ \\
\hline $\begin{array}{l}\text { Gender } \\
\text { M }\end{array}$ & $749(58 \%)$ & $504(74 \%)$ & $330(41 \%)$ & $459(40 \%)$ \\
W & $546(42 \%)$ & $173(26 \%)$ & $468(59 \%)$ & $679(60 \%)$ \\
Age & $55.3^{2,3}$ & $39.3^{1,3,4}$ & $50.0^{1,2,4}$ & \\
Mean & & & $54.5^{2,3}$
\end{tabular}


St. D. 16 .

Under 55 years old $\quad 46 \%$

Annual mileage

( $\mathrm{km})$

Mean

St. D.

Accidents

Mean

St. D.

$\%$ one or more

Range

Fines, parking

Mean

St. D.

$\%$ one or more

Range

$14682.3^{2,3,4}$
12266.9

$20705.8^{1,3,4}$

14001.7

$0.56^{1,3,4}$

1.02

35.0

1-10

$1.07^{1,3,4}$
3.94
35.6
$1-80$

$0.38^{1,3,4}$

0.91

25.9

1-10

1-3

$\%$ one or more

Range

0.48

Fines, other

Mean

$0.04^{2}$

St. D.

0.23

$\%$ one or more

3.4

Range

1-3

Note: $\mathrm{M}=$ men, $\mathrm{W}=$ women

Items in superscript indicate which means are significantly different from each other at a 0.05 level. For example, a 2 indicates that the cluster differs significantly from cluster 2 in regards for example age.

Table 6

Normal and preferred speed of the four clusters

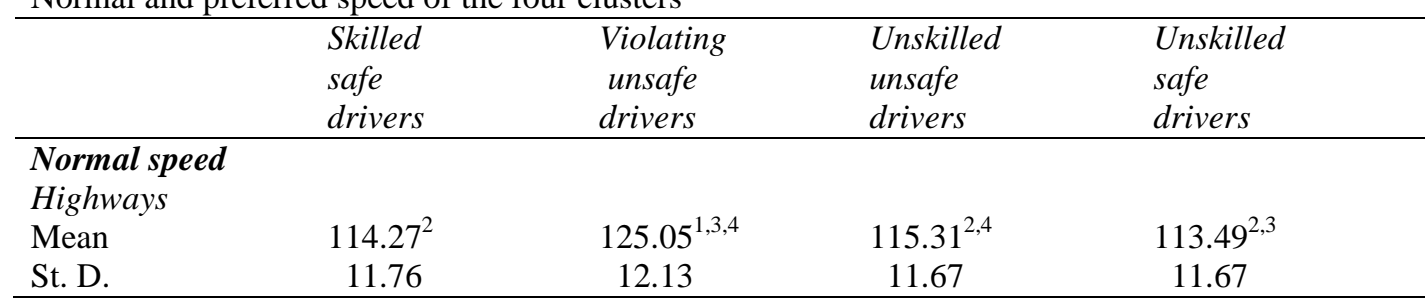




\begin{tabular}{lcccc}
\hline Other big roads & & & & \\
Mean & $82.21^{2}$ & $89.19^{1,3,4}$ & $83.31^{2}$ & $82.58^{2}$ \\
St. D. & 8.98 & 11.41 & 9.60 & 9.00 \\
City roads & & & & \\
Mean & $51.27^{2,3}$ & $54.49^{1,3,4}$ & $52.31^{1,2,4}$ & $51.15^{2,3}$ \\
St. D. & 5.28 & 8.01 & 7.78 & 5.75 \\
Rural roads & & & & \\
Mean & $80.45^{2}$ & $87.40^{1,3,4}$ & $81.54^{2,4}$ & $80.22^{2,3}$ \\
St.d & 7.94 & 10.04 & 9.14 & 9.02 \\
& & & & \\
Preferred speed & & & & \\
Highways & $117.37^{2,4}$ & $130.33^{1,3,4}$ & $117.75^{2,4}$ & $115.37^{1,2,3}$ \\
Mean & 13.91 & 13.03 & 13.19 & 13.05 \\
St. D. & & & & \\
Other big roads & $85.12^{2}$ & $92.81^{1,3,4}$ & $86.08^{2}$ & $84.83^{2}$ \\
Mean & 10.51 & 11.12 & 10.31 & 9.67 \\
St. D. & & & \\
City roads & $52.50^{2}$ & $55.76^{1,3,4}$ & $53.34^{2,3}$ & $52.17^{2,3}$ \\
Mean & 7.48 & 8.29 & 6.62 & 6.48 \\
St. D. & & & & \\
Rural roads & $82.93^{2}$ & $90.58^{1,3,4}$ & $83.86^{2,4}$ & $81.99^{2,3}$ \\
Mean & 9.84 & 10.65 & 10.34 & 10.06 \\
St. D. & & & \\
\hline Note. Items in superscript indicate which mans & & & \\
\hline
\end{tabular}

Note. Items in superscript indicate which means are significantly different from each other at a 0.05 level. For example, a 2 indicates that the cluster differs significantly from cluster 2 in regards for example rural roads. 